\title{
Adsorption purification of waste water from chromium by ferrite manganese
}

\author{
Liliia Frolova ${ }^{1, *}$, Mykola Kharytonov ${ }^{2}$, Iryna Klimkina ${ }^{3}$, Oleksandr Kovrov ${ }^{3}$, and Andrii \\ Koveria $^{3}$ \\ ${ }^{1}$ Ukrainian State University of Chemical Technology, 49005, Dnipro, Haharin Ave. 8, Ukraine \\ ${ }^{2}$ Dnipro State Agrarian And Economic University, 49600, Dnipro, Serhii Efremov Str., 25, Ukraine \\ ${ }^{3}$ Dnipro University of Technology, 49005, Dnipro, Yavornytskoho Ave., 19, Ukraine
}

\begin{abstract}
Plasma method is used to synthesize manganese ferrite. The basic properties of ferrite are determined by IR spectroscopy, UV spectroscopy, X-ray phase analysis, vibration magnetometry. The paper shows that the use of magnetically controlled sorbent allows to purify waste waters from chromium (III). The process of adsorption of chromium cations (III) is investigated. The kinetics of the process is studied. To describe the equilibrium isotherms, the experimental data are analysed by the models of Langmuir, Freundlich isotherms. Pseudo-first order, pseudosecond-order, and Weber-Morris are used to elucidate the kinetic parameters and mechanism of the adsorption process. It has been established that the removal of $\mathrm{Cr}$ (III) cations is described by the pseudosecond order of the Langmuir reaction and mechanism.
\end{abstract}

\section{Introduction}

Now mining and processing of minerals is a powerful environmental factor. The environmental impact of the mining industry is increasing. High level of wastewater pollution of the enterprises of the mining complex with heavy metal compounds and in particular chromium ions, leads to their migration, conversion to more toxic substances, accumulation in all components of the biosphere. It is known, for example, that mine and slagheap water contain chromium concentrations well in excess of MPC [1]. Its toxicity is highly dependent on the degree of oxidation. Chromium in the aqueous medium exists mainly in the trivalent $\mathrm{Cr}(\mathrm{III})$ or hexavalent $\mathrm{Cr}(\mathrm{VI})$ state. Hexavalent chromium compounds are one of the most dangerous substances for living organisms, even at low concentrations in water.

Ions are able to penetrate the cell membrane due to structural similarity to sulphates and react with intracellular material to interact with DNA. These substances have a pronounced carcinogenic and several other toxic effects. Cr(III) is less toxic. At the same time, the polyvalence of chromium leads to easy oxidation of $\mathrm{Cr}(\mathrm{III})$ to $\mathrm{Cr}(\mathrm{VI})$. In addition, the amphoteric character of chromium oxides and hydroxides facilitates the easy formation of soluble compounds in both acidic and alkaline environments. Therefore, the development of new wastewater treatment methods and technologies is very important [2].

*Corresponding author: 19kozak83@gmail.com 
There are many effective technologies for purification of chromium containing wastewater from chromium cations: reagent, electrochemical, membrane ultrafiltration, flotation [3-9]. The use of sorption technologies is promising. In recent years, adsorption has shown promising and effective results in both the drinking water and wastewater treatment technologies of industry [10]. Advantages of adsorption technologies are high degree of purification, high capacity, easy regeneration methods and secondary use.

However, in order to effectively apply adsorption methods in various industries, it is necessary to solve some problems of their use, such as high capital costs, difficult separation of the adsorbent from solution, complex processes of synthesis.

Adsorbents of different nature, structure and mechanism of action are used to purify chromium-containing wastewater. For example, adsorbents commonly used to purify water from chromium cations are activated by carbon, silica gel, zeolite, clay minerals, slag [11-15]. However, these types of adsorbents have one common drawback - they require a long separation of solution, which increases operating costs. To prevent this problem, some probes offer magnetic materials that can be promising adsorbents that can be easily separated from the solution by a magnetic field $[15,16]$. Ferrite magnetic adsorbents can provide fast and efficient separation of suspensions. The study of the possibility of using ferrites in environmental technologies related to the removal of heavy metals is relevant.

The properties of ferrites depend on the cationic composition, particle morphology, which is conditioned by technological process parameters. Currently, many researchers investigate the effect of various synthesis parameters on the technological properties of ferrites. For example, the nature of cations in nanoferrites $\left(\mathrm{MFe}_{2} \mathrm{O}_{4}, \mathrm{M}=\mathrm{Co}, \mathrm{Ni}, \mathrm{Cu}\right)$ [16]. Nanodispersed ferrite $\mathrm{Mn}$ has a developed surface area and high magnetic characteristics; therefore, it can be assumed that the adsorbent is rapidly separated from the aqueous solution.

In this work, the adsorption of chromium cations by the adsorbent $\mathrm{MnFe}_{2} \mathrm{O}_{4}$ is studied.

\section{Materials and Methods}

$\mathrm{MnFe}_{2} \mathrm{O}_{4}$ nanoparticles are obtained by chemical precipitation from aqueous solution of ferrous (II) sulphate, manganese (II) sulphate by the method described in detail in [18].

The processing is carried out in a cylindrical reactor with an inner diameter of $45 \mathrm{~mm}$ and a height of $85 \mathrm{~mm}$. The reaction mixture was cooled by continuous circulation of cold water in the outer jacket. The electrodes were made of stainless steel, one of which (with a diameter of $4 \mathrm{~mm}$ ) was located in the lower part of the reactor, and the other (with a diameter of $2.4 \mathrm{~mm}$ ) was placed above the solution surface at a distance of $10 \mathrm{~mm}$. To obtain a plasma discharge, a voltage of $500 \mathrm{~V}$ was applied to the electrodes $1000 \mathrm{~V}$. A vacuum pump was used to reduce the pressure in the reactor. Obtaining coprecipitated compounds are carried out by pouring with continuous stirring the corresponding mixture of sulphate solutions with the desired ratio of cations, as in ferrite (analytical purity). Subsequent treatment is carried out with plasma for 30 minutes.

The resulting suspension was separated on a magnetic filter and dried at $100-150{ }^{\circ} \mathrm{C}$ for 2 hours.

Fourier transformed infrared spectra (FTIR) were recorded using a Nicolet iS10, Thermo Scientific, spectrometer with synthesized powder samples. To study the transformations that occur during heating of the obtained powders, we used the method of differential thermal analysis (DTA) and differential thermogravimetric analysis (DTG). DTA curves, TG mass loss, and DTG mass loss rates were recorded on a Derivatograph Q1500D derivatograph (F. Paulik, J. Paulik, L. Erdey systems). The morphology of the ferrite powders and their size were investigated using scanning electron microscopy. X-ray 
analysis of the samples is performed on a DRON-2 diffractometer. Mode of operation of the X-ray source is $40 \mathrm{kV}, 30 \mathrm{~mA}$. $2 \theta$ scan angle range from $10^{\circ}$ to $90^{\circ}$.

The sorption properties of manganese ferrite are revealed by determining the degree of sorption of chromium (III) cations at different initial concentration.

The initial concentration of $\mathrm{Cr}$ (III) in the model wastewater solutions was $0.01 \mathrm{~mol} / \mathrm{l}$, $0.025 \mathrm{~mol} / \mathrm{l}, 0.05 \mathrm{~mol} / \mathrm{l}$.

The concentration of adsorbent in the model solutions also varied. The degree of sorption was calculated by reducing the concentration of chromium cations in aqueous solution by the formula:

$$
S=\frac{C_{0}-C_{t}}{C_{0}} 100 \%
$$

where $C_{0}$ and $C_{t}$ are the initial concentrations as well as the concentrations of metal ions after adsorption in solutions, respectively ( $\mathrm{mol} / \mathrm{l})$.

\section{Results and discussion}

\subsection{Characteristics of the adsorbent}

In the first stage we investigated the X-ray composition of manganese ferrite. As can be seen from the radiographs presented at the Figure 1, there is an amorphous crystalline substance having the general formula $\mathrm{MnFe} 2 \mathrm{O} 4$. The most intense peaks are characteristic of spinel. The structure is observed at $2 \theta$ about $35^{\circ}$. All the peaks correspond to the cubic structure of spinels, but their small intensity and some extension characterize the nanodispersed state of manganese ferrite. The size of the lattice parameter for the sample is $8.4313 \mathrm{~A}$.

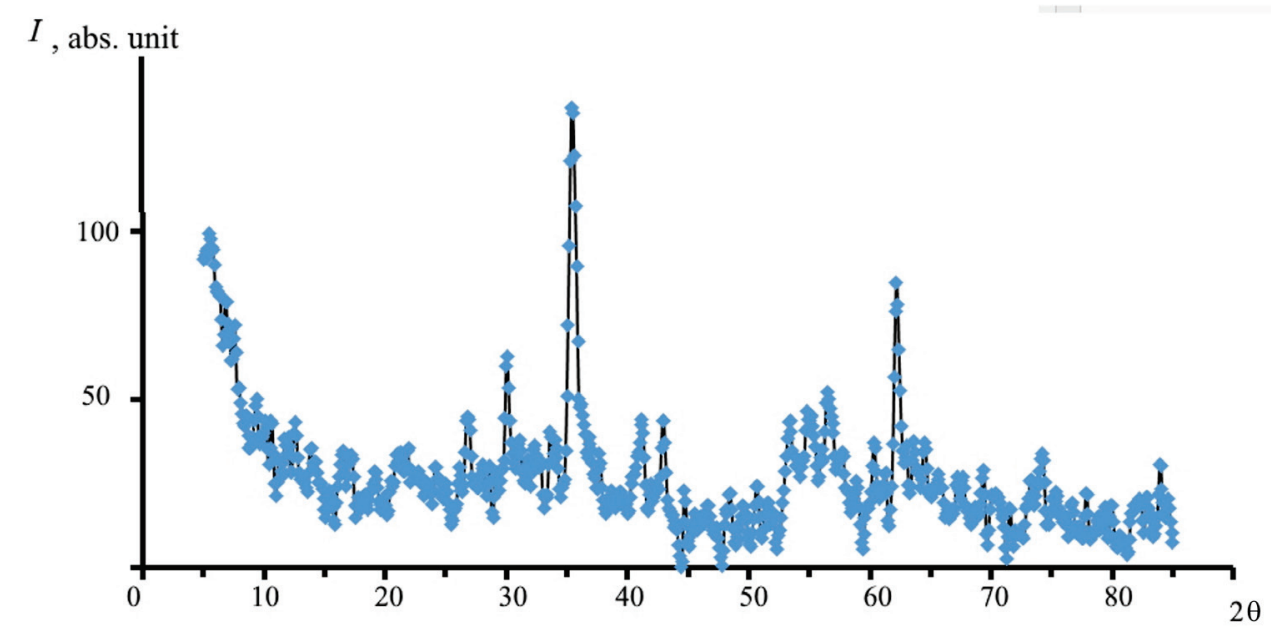

Fig. 1. X-ray diffractogram of manganese ferrite.

FTIR spectra in the range $3900-350 \mathrm{~cm}^{-1}$ for $\mathrm{FeMn}_{2} \mathrm{O}_{4}$ are shown in Figure 2.

FTIR spectra revealed only specific vibration bands of the metal tensile oxygen from the tetrahedral sublattice in the range $580-540 \mathrm{~cm}^{-1}$ and from the $400-420 \mathrm{~cm}^{-1}$ octahedral site. Also shown is a plateau of 2900-3400 $\mathrm{cm}^{-1}$, which corresponds to the presence of bound water. The presence of this band is explained by the hydrophase lowtemperature method of producing manganese ferrite. The high adsorption capacity can 
be ensured by the presence of crystallization moisture corresponding to the peaks on the FTIR spectra.

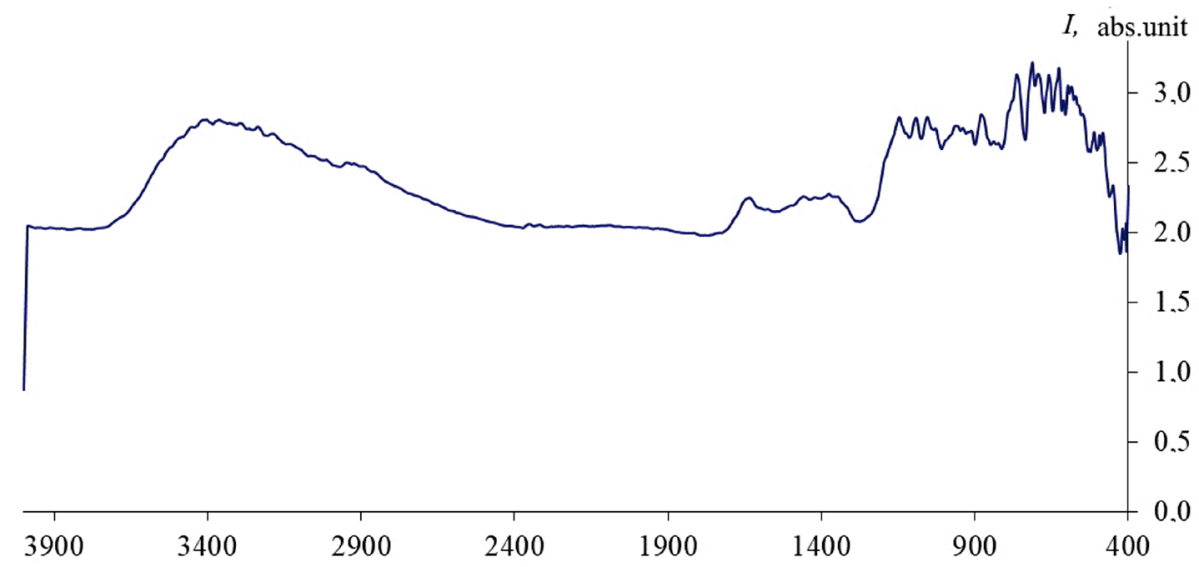

Fig. 2. FTIR spectra of manganese ferrite.

Also important is the specific size and shape of the manganese ferrite particles. According to electron microscopy, all the plasma-synthesized samples consist of irregularly shaped particles whose sizes vary from $150 \mathrm{~nm}$ to $1.6 \mu \mathrm{m}$ (Fig. 3). The most common are agglomerates with sizes of $650-800 \mathrm{~nm}$. The observed boundary particles are polycrystalline. Large ferrite particles consist of very small primary particles. The calculated crystallite size is $48.8 \mathrm{~A}$.

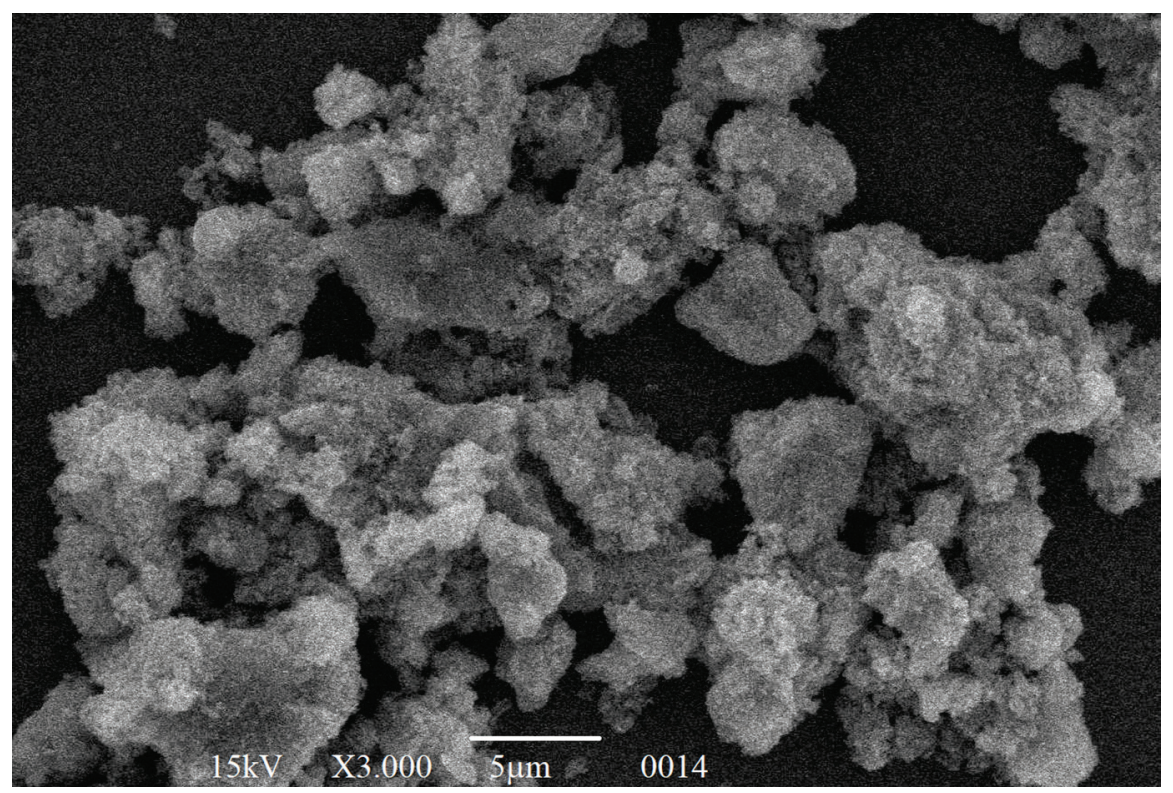

Fig. 3. SEM micrograph of manganese ferrite.

Figure 4 shows the derivatogram of manganese ferrite. DTG curves show that for all formulations the main mass loss corresponds to the loss of free water and at the temperature of $100{ }^{\circ} \mathrm{C}$ and bound at the temperature of $140{ }^{\circ} \mathrm{C}$.

The DTA curve exhibits exothermic peaks corresponding to the oxidation reactions of manganese cations to different degrees of oxidation. 


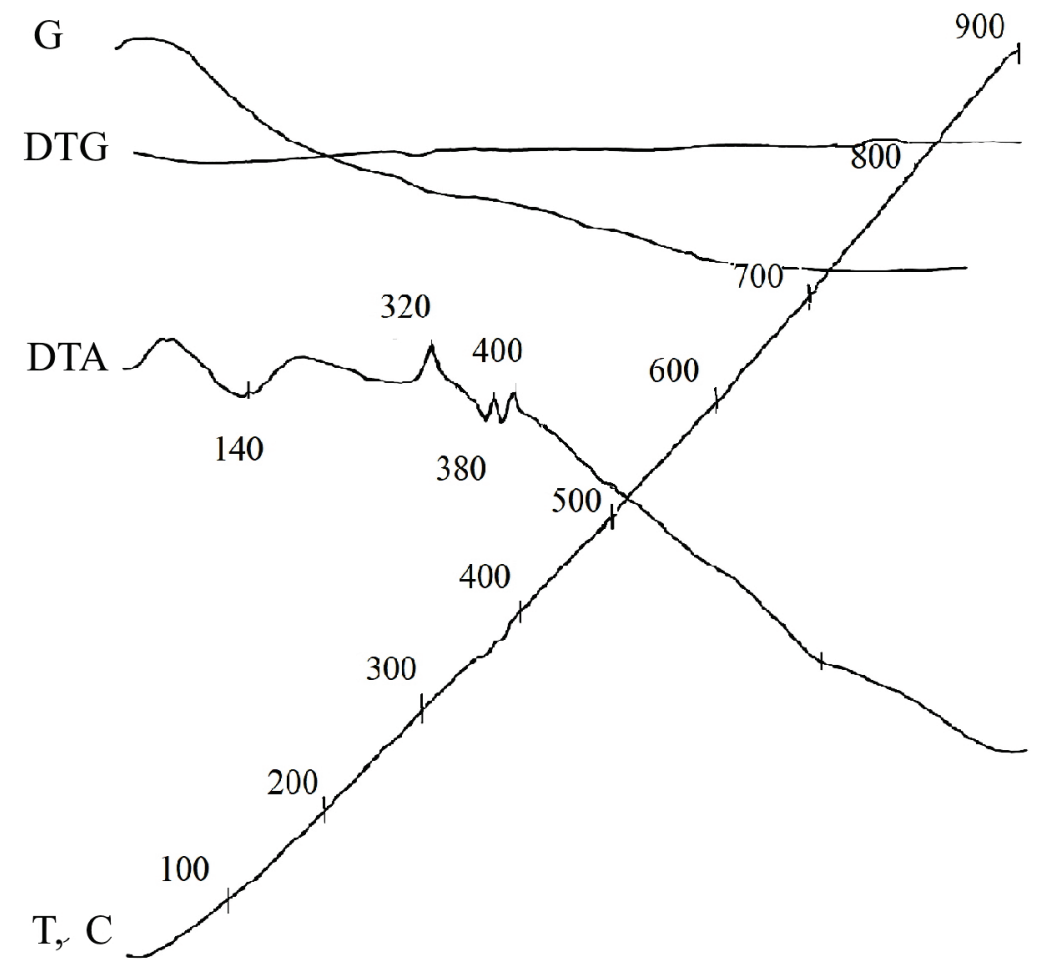

Fig. 4. Derivatogrammes of manganese ferrite.

The ferrite sample obtained has a high magnetization values. As shown in Figure 5, the hysteresis loop corresponds to a coercive force of $11 \mathrm{Oe}$. The large values of saturation magnetization make it easy to separate the adsorbent and provide a high degree of purification.

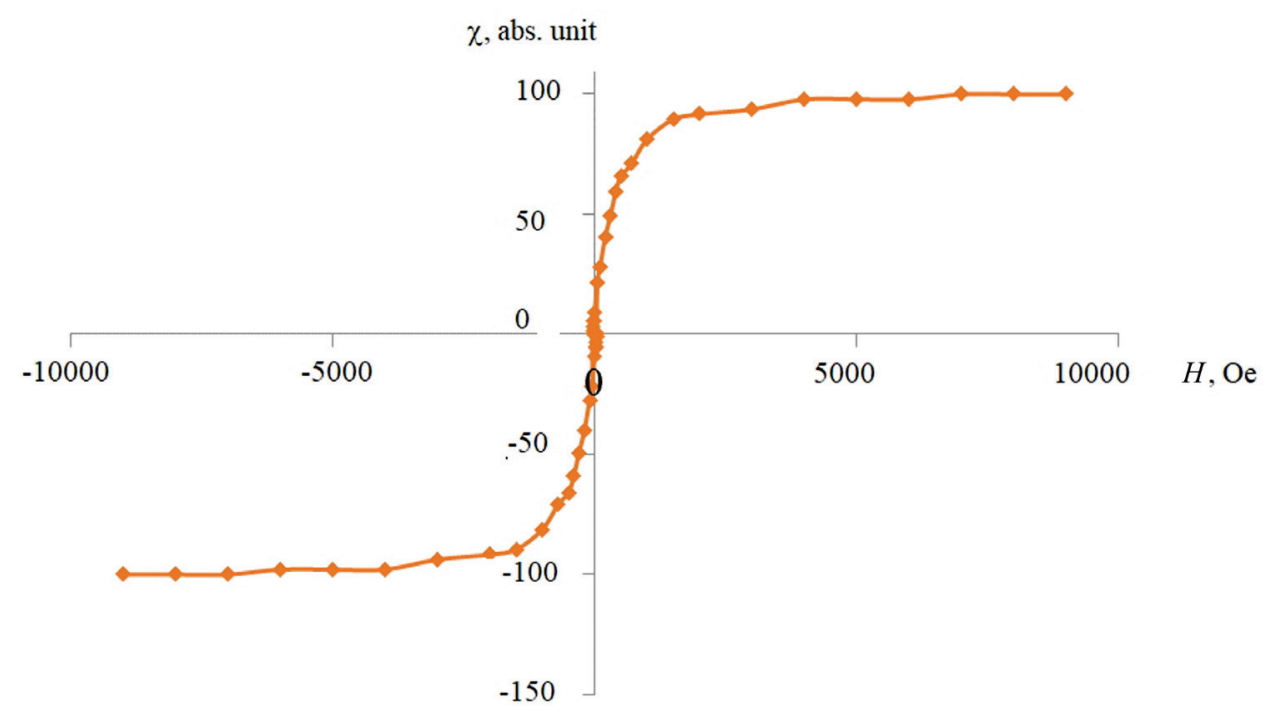

Fig. 5. Hysteresis loop of manganese ferrite. 


\subsection{Investigation of adsorption characteristics}

The Figure 6 presents the dependence of the degree of purification on the mass of the adsorbent. The dependence of the degree of sorption on the mass of adsorbents is almost linear in nature. The maximum sorption capture was $82-98 \%$. As the initial concentration of the solution increases, the degree of purification increases as well.

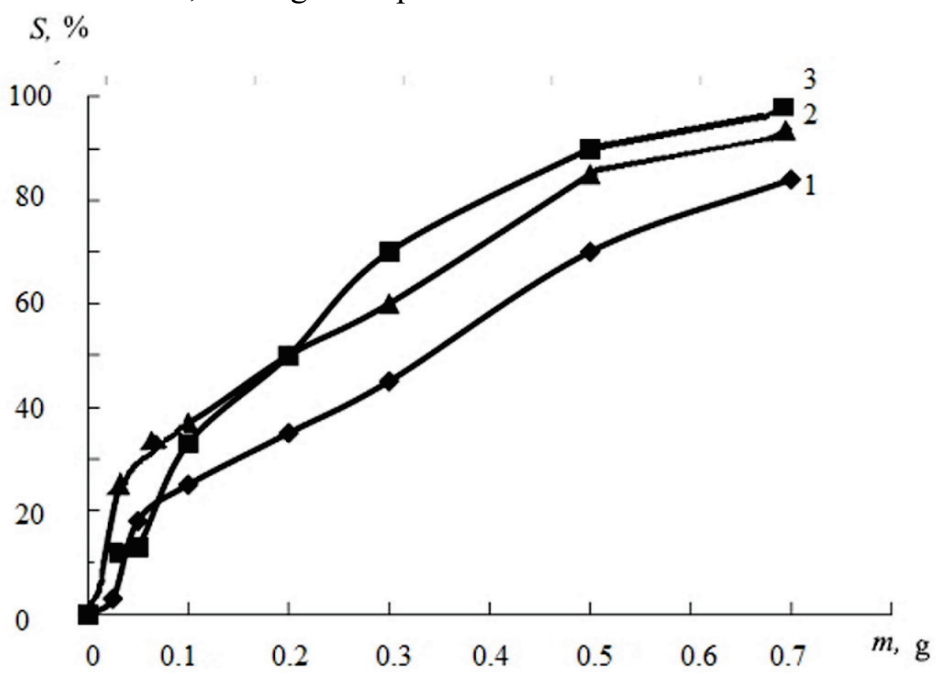

Fig. 6. Dependence of the degree of purification on the mass of the $\mathrm{MnFe}_{2} \mathrm{O}_{4}$ adsorbent $(\mathrm{g} / 50 \mathrm{ml})$ : 1- $0.005 \mathrm{~mol} / 1,2-0.01 \mathrm{~mol} / 1,3-0.015 \mathrm{~mol} / \mathrm{l}$.

Along with sorption capacity, an important indicator that determines the possibility of using the sorbent for practical purposes is the dependence of the sorption process in time. Kinetic characteristics are determined by the external and internal diffusion or the process of chemisorption. Experimental sorption experiments were commonly used to study sorption phenomena (Fig. 7). To determine the kinetic characteristics of the process of sorption of chromium ferric ions of manganese, kinetic dependences were processed in the coordinates corresponding to the pseudo-first, pseudo-second and pseudo-third order of the reaction. The linear and nonlinear forms of these equations and their parameters are summarized in Table 1. The results of the calculations are shown in Table 2.

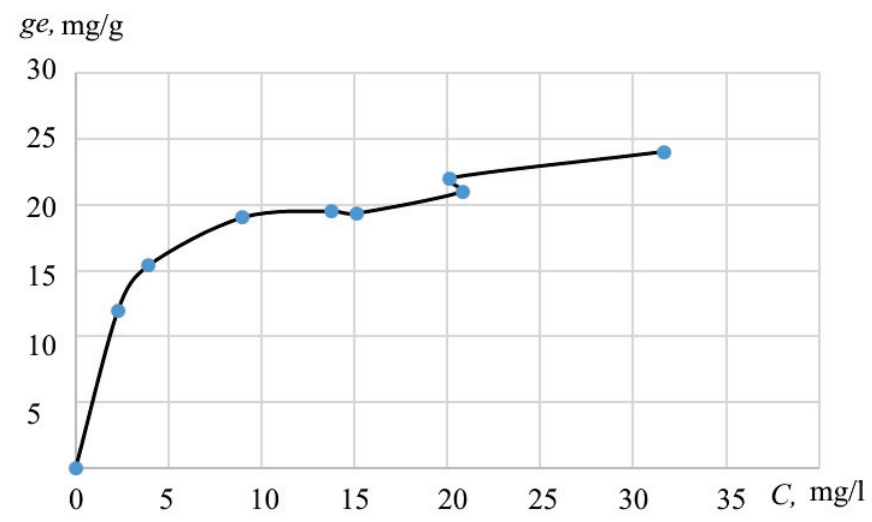

Fig. 7. Isotherm of adsorption of $\mathrm{Cr}^{3+}$ ions for manganese ferrite sorbent $\mathrm{m}_{\mathrm{s}}=1.0 \mathrm{~g} ; \mathrm{Vs}=100 \mathrm{ml}$; $\mathrm{T}=298 \pm 1 \mathrm{~K}$, sorption duration of 8 hours. 
Table 1. Results of calculations of kinetic curves.

\begin{tabular}{|c|c|c|c|}
\hline \multirow{2}{*}{ Model } & \multicolumn{2}{|c|}{ Equation } & \multirow{2}{*}{ Parameters } \\
\hline & linear & nonlinear & \\
\hline $\begin{array}{l}\text { Langmuir } \\
\text { isotherms }\end{array}$ & $\frac{C_{e}}{q_{e}}=\frac{1}{K_{L} Q_{m}}+\frac{C_{e}}{Q_{m}}$ & $q_{e}=\frac{Q_{m} K_{L} C_{e}}{1+K_{L} C_{e}}$ & $\begin{array}{l}C_{e} \text { is the equilibrium } \\
\text { concentration of the solute } \\
(\mathrm{mg} / \mathrm{l}), q_{e} \text { is the amount of } \\
\text { solute per unit weight at } \\
\text { equilibrium }(\mathrm{mg} / \mathrm{g}), Q_{m} \text { is the } \\
\text { maximum sorption capacity of } \\
\text { the Langmuir monolayer }\end{array}$ \\
\hline $\begin{array}{l}\text { Freundlich } \\
\text { isotherms }\end{array}$ & $\begin{array}{l}\log q_{e}= \\
=\log K_{F}+\frac{1}{n} \log C_{e}\end{array}$ & $q_{e}=K_{F} C_{e}^{1 / n}$ & $\begin{array}{l}C_{e} \text { and } q_{e} \text { are the equilibrium } \\
\text { concentration of the adsorbate } \\
(\mathrm{mg} / \mathrm{l}) \text { and the adsorption } \\
\text { substance adsorbed per unit } \\
\text { weight at equilibrium ( } \mathrm{mg} / \mathrm{g}) \text {, } \\
K_{F} \text { is the Freundlich constant } \\
\text { associated with the adsorption } \\
\text { capacity }(\mathrm{mg} / \mathrm{g})\end{array}$ \\
\hline $\begin{array}{l}\text { Kinetics } \\
\text { pseudo-first } \\
\text { order }\end{array}$ & $\begin{array}{l}\log \left(q_{e}-q_{t}\right)= \\
=\log \left(q_{e}\right)-\left(\frac{k_{1}}{2.33}\right) t\end{array}$ & $q_{t}=q_{e}\left(1-e_{e}^{-k 1 t}\right)$ & $\begin{array}{l}k_{1} \text { is the first-order equation, } \\
q_{t} \text { is the amount adsorbed in } \\
\text { time t, } \\
q_{e} \text { is the amount adsorbed at } \\
\text { equilibrium }\end{array}$ \\
\hline $\begin{array}{l}\text { Kinetics } \\
\text { pseudo- } \\
\text { second order }\end{array}$ & $\frac{t}{q_{t}}=\frac{1}{k_{2} q_{e}^{2}}+\frac{t}{q_{e}}$ & $q_{t}=\frac{q_{e}^{2} k_{2} t}{1+q_{e} k_{2} t}$ & $\begin{array}{l}k_{2} \text { is the second level equation, } \\
q_{t} \text { and } q_{e}-\text { the amount of } \\
\text { adsorbate is adsorbed in time } \mathrm{t} \\
\text { and equilibrium }\end{array}$ \\
\hline $\begin{array}{l}\text { Kinetics } \\
\text { Weber- } \\
\text { Morris } \\
\text { equation }\end{array}$ & $q_{t}=k_{t} t^{1 / 2}$ & & $\begin{array}{l}k_{t} \text { is the diffusion rate constant } \\
\text { within the particle, } C \text { is the } \\
\text { intercept (boundary layer } \\
\text { effect) }\end{array}$ \\
\hline
\end{tabular}

Table 2. Summary results of calculations.

\begin{tabular}{|l|c|c|c|}
\hline \multicolumn{1}{|c|}{ Model } & Options & $\begin{array}{c}\text { Coefficient } \\
\text { correlation }\end{array}$ & $\begin{array}{c}\text { Constanta rate } \\
\text { adsorption }\end{array}$ \\
\hline Langmuir isotherms & $1 / q_{e}=0.214 C_{e}+2.431$ & $R=0.97$ & \\
\hline Freundlich isotherms & $\log q_{e}=0.021 \log C_{e}+2.5561$ & $R=0.76$ & $R=0,46$ \\
\hline $\begin{array}{l}\text { Kinetics pseudo-first } \\
\text { order }\end{array}$ & $\log \left(q_{e}-q_{t}\right)=0.017 t+1.188$ & $\begin{array}{c}K_{I}=0.0168 \\
(1 / \mathrm{min})\end{array}$ \\
\hline $\begin{array}{l}\text { Kinetics pseudo-second } \\
\text { order }\end{array}$ & $1 / q_{t}=0.059 t+1.273$ & $R=0.98$ & $\begin{array}{c}K_{2}=0.0588 \\
\left(1 / \mathrm{min}^{2}\right)\end{array}$ \\
\hline $\begin{array}{l}\text { Kinetics Weber-Morris } \\
\text { equation }\end{array}$ & $q_{t}=3.662 t+17.407$ & $R=0.94$ & $K t=3.66$ \\
\hline
\end{tabular}

The analysis of adsorption isotherm is important for predicting the adsorption capacity of manganese ferrite, which is one of the main parameters of the process. The equilibrium isotherm was studied using different models.

The most widely used isotherms were Langmuir and Freundlich equations, and the most 
common pseudo-first and pseudo-second order kinetic equations [19]. The Langmuir model was used to analyse the equilibrium adsorption data, which is the simplest description of the adsorption process.

Thus, the best equation that properly describes the experimental data is the pseudosecond order reaction and the Langmuir mechanism.

\section{Conclusions}

Manganese ferrite adsorbents have sorption properties due to ion exchange and interaction with $\mathrm{OH}^{-}$groups present on the surface.

The results of the experiments showed that manganese ferrite can be effectively used to remove $\mathrm{Cr}$ (III) from wastewater.

Simulation of the sorption equilibrium has shown that kinetic dependences are described by the second order equation. The adsorption isotherm is described by the Langmuir equation.

The results obtained may form the basis for further studies related to the use of magnetic adsorbents in wastewater treatment technologies.

\section{References}

1. Pavlichenko, A.V., Kulina, S.L. (2015). Ekologichna nebezpeka girnichih vidhodiv likvidovanih shaht Chervonograds'kogo girnichopromislovogo regionu. Zbirnik naukovih prac' NGU, (48), 216-223

2. X. He, P. Li J. Expo. Sci. Environ. Epidemiol, 1-17 (2020)

3. J.R.Werber, C. O.Osuji, M. Elimelech Nat. Rev. Mater., 1, 5 (2016)

4. A. Pratush, A.Kumar, Z. Hu Int Microbiol, 21, 3 (2018)

5. D. Khawaji, I.K. Kutubkhanah, J. M. Wie, Desalination, 221, 1-3 (2008).

6. N.M. Rakhi, S. Dayanand Arch Pet Environ Biotechnol, 105 (2017)

7. M. Hua, S. Zhang, B. Pan, W. Zhang, L.Lv, Q. Zhang, J. Hazard. Mater., 211, (2012)

8. E. Bazrafshan, L. Mohammadi, A. Ansari-Moghaddam, A.H. Mahvi J Environ Health Sci 13, 1 (2015)

9. A. Azimi, A. Azari, M. Rezakazemi, M. Ansarpour ChemBioEng Reviews, 4, 1 (2017)

10. L. Frolova, M. Kharytonov Adv Mater Sci Eng (2019)

11. M.V.S. Kumar, G.J. Shankarmurthy, E. Melagiriyappa, K.K. Nagaraja, H.S. Jayanna, M.P. Telenkov J. Mater. Sci. Mater. Electron. 29, 15 (2018)

12. M. Coll, J.M. Montero Moreno, J. Gazquez, K. Nielsch, X. Obradors, T. Puig Adv. Funct. Mater., 24(34), 5368-5374 (2014)

13. L. Frolova, A. Pivovarov Chem.Chem.Technol., 10, 2 (2016)

14. L.A. Frolova, A.A. Pivovarov, T.E. Butyrina, E.G. Tsepich J Water Chem Techno, 37, 4 (2015)

15. L. A.Frolova, A.A. Pivovarov, L.B. Anisimova, Z.N. Yakubovskaya, A.I. Yakubovskii Voprosy Khimii i Khimicheskoi Tekhnologii, 6, (2017)

16. A. Subramani, J. G. Jacangelo Water Res, 75, (2015)

17. D. Mehta, S. Mazumdar, S. K. Singh J Water Process Eng, 7, (2015)

18. L. A. Frolova, M. P. Derhachov Nanoscale Res. Lett., 12, 1 (2017)

19. A. E. Regazzoni Colloids Surf. A Physicochem. Eng. Asp, 585, (2020) 